\title{
Microwave Measurements of the Dielectric Properties of Silicon Carbide at High Temperature
}

\author{
Thoria A. Baeraky \\ Faculty of Science, Physics Department, King Abdulaziz University, \\ Jeddah, Saudi Arabia
}

\begin{abstract}
The dielectric properties of silicon carbide SiC have been measured using cavity perturbation technique. Three tubes with diameter $2 \mathrm{~mm}, 3 \mathrm{~mm}$, and $5 \mathrm{~mm}$ were filled with the powerful material of SiC. The measurements were taken for each tube at different frequencies $0.615 \mathrm{GHz}, 1.412 \mathrm{GHz}, 2.214$ $\mathrm{GHz}, 3.017 \mathrm{GHz}$ and $3.820 \mathrm{GHz}$ in a temperature range from $25^{\circ} \mathrm{C}$ to $1800^{\circ} \mathrm{C}$. The electrical conductivity and the activation energy of $\mathrm{SiC}$ at the above frequencies and temperatures were calculated using the measured real and imaginary components of the complex permittivity.
\end{abstract}




\section{Introduction:}

Microwave processing of ceramics has been attracting significant attention in recent years [1-3]. Microwave heating is a new source of energy; it works inside the material and simultaneously heats the bulk of the material. Rapidly developing capability is being established in the field of high power microwave processing of ceramics. This technique has distinct advantages in reducing the time and temperature of processing as well as improving the homogeneity of heating [4]. Sintering and joining ceramics are the most important processes of microwave heating where these two processes need volumetric heating which can not be achieved when using conventional heating [5-7]. Various microwave oxide and nonoxide ceramics have been developed in line with the recent rapid growth of microwave processing that these materials have physical and chemical properties make them appropriate for use in advanced engine design and other applications [8-10]. Silicon carbide is a good example of microwave processing materials. It is a nonoxide ceramic, which needs "ultra" high temperature and volumetric heating to process it [11]. Joining the reaction bonded $\mathrm{SiC}$ to itself and sintered $\mathrm{SiC}$ have been found to be feasible using microwave energy [12]. Unfortunately the growing of microwave processing of ceramics faced with two problems, thermal runaway and the nonuniform heating, which are caused by a number of factors related to both electromagnetic energy and thermal physical process [13]. Understanding the microwave-materials interaction leads to overcome these problems that the materials interact with cold microwave rays and converts the microwave energy to heat, which means that the rate of the heat inside the material depends on the rate of the microwave absorption. It was shown that the rate of microwave absorption depends on the magnitude of the dielectric properties [14]. Theoretical and experimental works have shown that the increase of dielectric properties of material with temperature can lead to uniform and enhanced microwave power absorption in ceramics $[15,16]$. Hence the dielectric properties of ceramics at high temperature and at the microwave strong field must be known so that microwave processing ceramics can be controlled. In recent years, the measurement of complex dielectric properties has been becoming more important. Different methods with different techniques have been used for successful measurements of the dielectric properties of materials [17-19]. Cavity perturbation technique provides a bridge between theoretical calculation and experimental observation and it does not have a special requirement for the geometry and size of the measured sample [20].

In this paper the dielectric properties of $\mathrm{SiC}$ are measured using the cavity perturbation technique. This technique has been developed to measure the dielectric properties of ceramics at high temperature up to $2000{ }^{\circ} \mathrm{C}$ in the five modes of the cavity; $\mathrm{TM}_{101}, \mathrm{TM}_{102}, \mathrm{TM}_{103}, \mathrm{TM}_{104}$, and $\mathrm{TM}_{105}$, of frequency 
values, $0.615 \mathrm{GHz}, 1.412 \mathrm{GHz}, 2.214 \mathrm{GHz}, 3.017 \mathrm{GHz}$ and $3.820 \mathrm{GHz}$ respectively [21].

\section{Experimental Procedure:}

The measurements system, the cavity perturbation technique, is shown in Fig. (1). It was developed by [21] to measure the dielectric properties of materials with conventional furnace in the temperature range of $25^{\circ} \mathrm{C}-2000{ }^{\circ} \mathrm{C}$ and a resonator cavity resonates at five modes of frequency values, $0.615 \mathrm{GHz}$, $1.412 \mathrm{GHz}, 2.214 \mathrm{GHz}, 3.017, \mathrm{GHz}$ and $3.820 \mathrm{GHz}$ respectively. It is computer-automated system in measuring the resonant frequencies of the cavity with and without the sample, $f$ and $f_{o}$, respectively, the quality factors of the cavity with and without the sample, $\mathrm{Q}$ and $\mathrm{Q}_{\mathrm{o}}$, respectively. The change in these quantities, $\mathrm{f}, \mathrm{f}_{\mathrm{o}}, \mathrm{Q}$, and $\mathrm{Q}_{\mathrm{o}}$, are related to the dielectric properties of the sample by the simple perturbation formula derived by Nakamura and Furuichi [22].

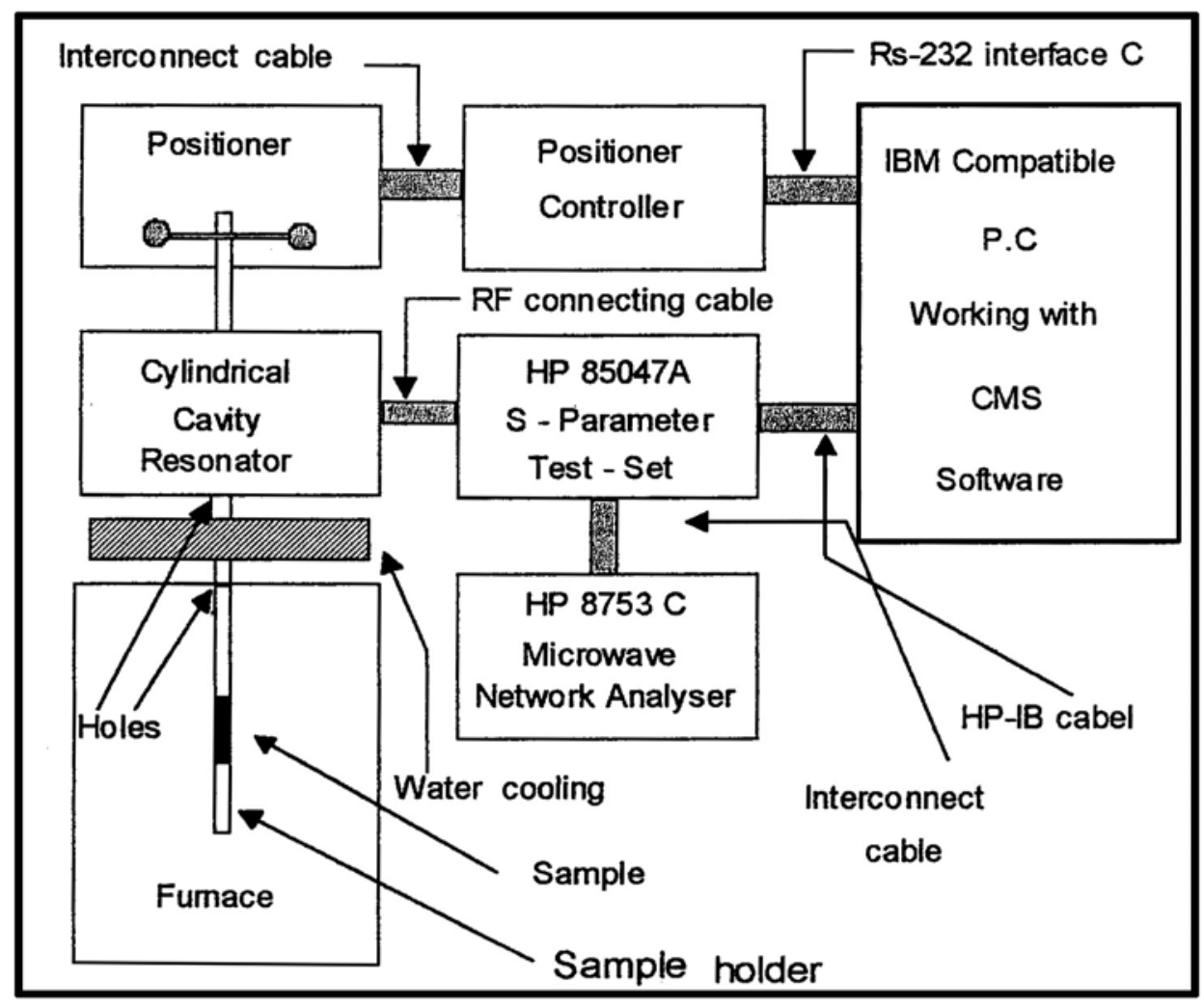

Fig. (1) : Experimental setup [21]. 


$$
\begin{aligned}
& \varepsilon^{\prime}=2 \mathrm{j}^{2}\left(\chi_{\text {on }}\right) \frac{\mathrm{a}^{2}}{\mathrm{~b}^{2}} \frac{\Delta \mathrm{f}}{\mathrm{f}}+1 \\
& \varepsilon^{\prime \prime}=2 \mathrm{j}^{2}\left(\chi_{\text {on }}\right) \frac{\mathrm{a}^{2}}{\mathrm{~b}^{2}} \Delta\left(\frac{1}{\mathrm{Q}}\right)
\end{aligned}
$$

where $\chi_{\text {on }}$ is the root of the zero order Bessel function of the first kind and a and $\mathrm{b}$ are the sample and the cavity volumes respectively. $\Delta \mathrm{f}$ and $\Delta(1 / \mathrm{Q})$ are the change in resonant frequency and reciprocal Q respectively on insertion of the sample into the cavity.

High purity $(>99.0 \%) \mathrm{SiC}$ powder was used in this study. The measurements were taken for different quantities of the sample where three tubes of diameters, $2 \mathrm{~mm}, 3 \mathrm{~mm}$, and $5 \mathrm{~mm}$ were filled by $\mathrm{SiC}$.

\section{Results and Discussion:}

The change of permittivity real, $\varepsilon^{\prime}$, and imaginary, $\varepsilon^{\prime \prime}$, parts of the three samples of $\mathrm{SiC}$ versus the changing of temperature and frequencies are shown in Figures 2-4.
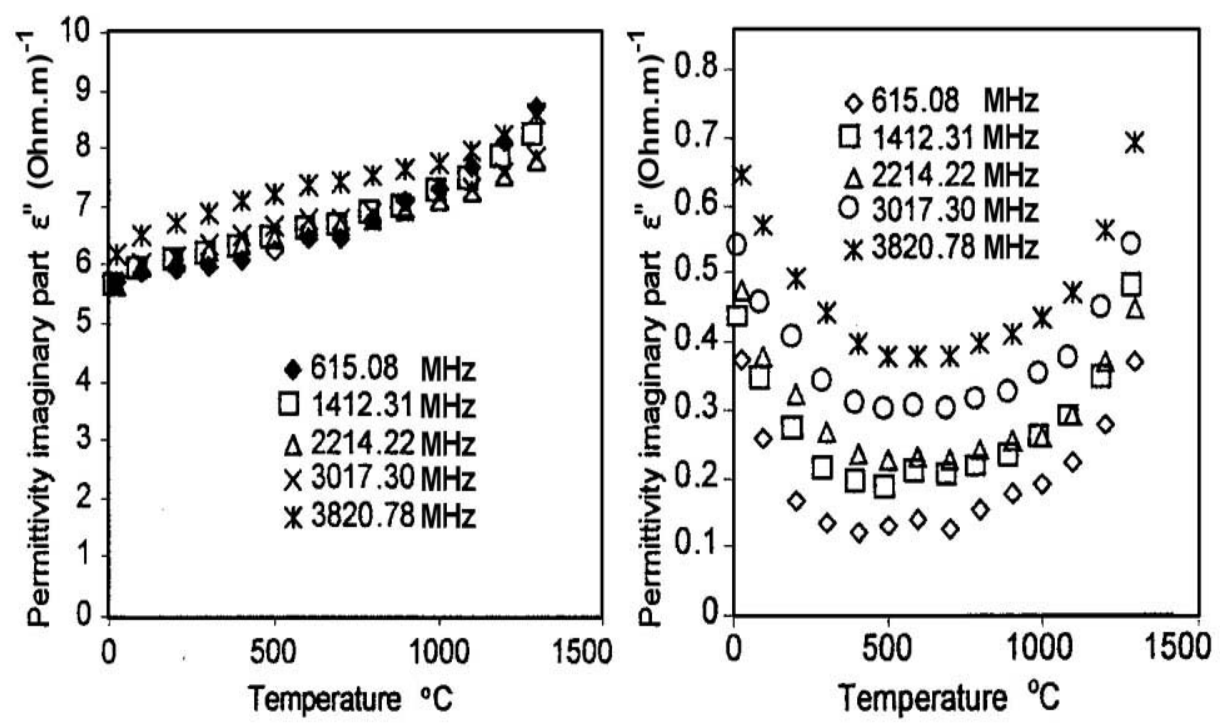

Fig. (2): Temperature dependence of permittivity (real \& imaginary) of $\mathrm{SiC} \phi 2 \mathrm{~mm}$ diameter). 

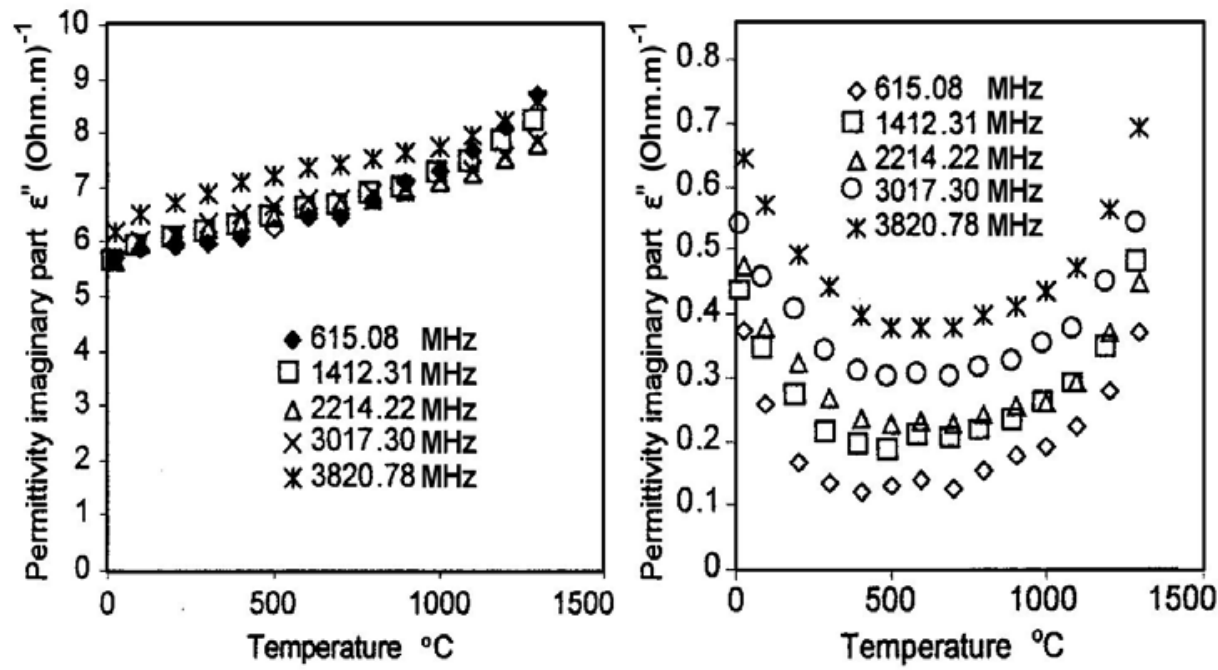

Fig. (3): Temperature dependence of the permittivity (real and imaginary) of SiC (3 mm diameter).
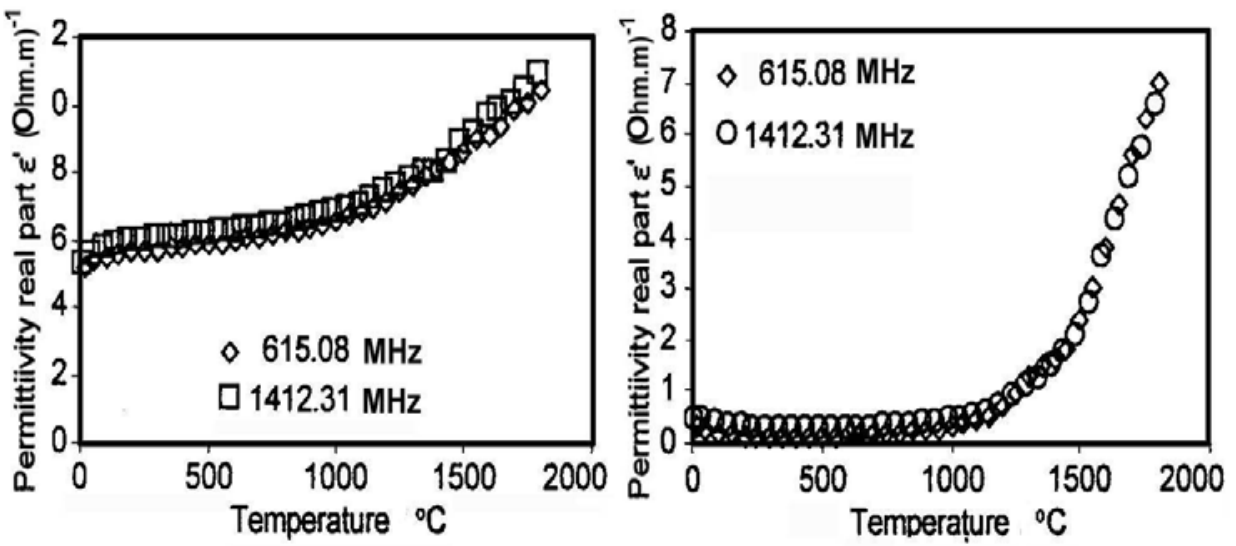

Fig. (4): Temperature dependence of the permittivity (real and imaginary) of SiC (5 mm diameter).

Silicon carbide ceramics have a high dielectric loss at room temperature and the cavity perturbation theory works with low dielectric loss. Tube contains a light amount of $\mathrm{SiC}$ powder becomes low dielectric SiC. Figures 2-4 show that the system measurement caught the five modes for the sample of small quantity, $2 \mathrm{~mm}$ in diameter, while for the others, $3 \mathrm{~mm}$ and $5 \mathrm{~mm}$ in diameter, it caught only four and two modes respectively. The samples of $\mathrm{SiC}$ of $2 \mathrm{~mm}$, $3 \mathrm{~mm}$, and $5 \mathrm{~mm}$ in diameters were heated from $25^{\circ} \mathrm{C}$ up to $1400^{\circ} \mathrm{C}, 1600^{\circ} \mathrm{C}$, and $1800^{\circ} \mathrm{C}$ respectively. Figures $2-4$ show that the increasing of the samples' real parts with the increasing of temperature is regularly and significant, while the 
increasing of its imaginary parts with the increasing of temperature is exponential, except the sample in Figure 2. The maximum temperature of this sample is $1400^{\circ} \mathrm{C}$ while the maximum temperatures of the other samples, shown in Figure 3-4, are $1600^{\circ} \mathrm{C}$ and $1800^{\circ} \mathrm{C}$ respectively. This means that the microwave absorption of this material, $\mathrm{SiC}$, is significant when the temperature is below $1400^{\circ} \mathrm{C}$ as shown in Figure 2 , and increases exponentially when the temperature is above $1400^{\circ} \mathrm{C}$, thermal runaway. They occurred as shown in Figure 3 and 4 . The frequency dependence, of the imaginary parts of the sample of $2 \mathrm{~mm}$ in diameter, is obviously shown in Figure 2, where the temperature did not reach to the thermal runaway. They are increasing with the increasing of frequency.

It was shown that the relationship between the electrical conductivity, $\sigma$, and the imaginary part, $\varepsilon^{\prime \prime}$, is [23]

$$
\sigma_{\mathrm{a} . \mathrm{c}}=2 \pi \mathrm{f} \varepsilon_{\mathrm{o}} \varepsilon^{\prime \prime}
$$

where $f$ and $\varepsilon_{0}$ are the resonant frequency of the sample and the permittivity of free space respectively. By using the data of $\varepsilon^{\prime \prime}$ in Figures 2 - 4, the conductivity, can be derived from equation (3). The variation of the conductivity with temperature in the presence of a strong microwave field is shown in Figs. (5 \& 6).

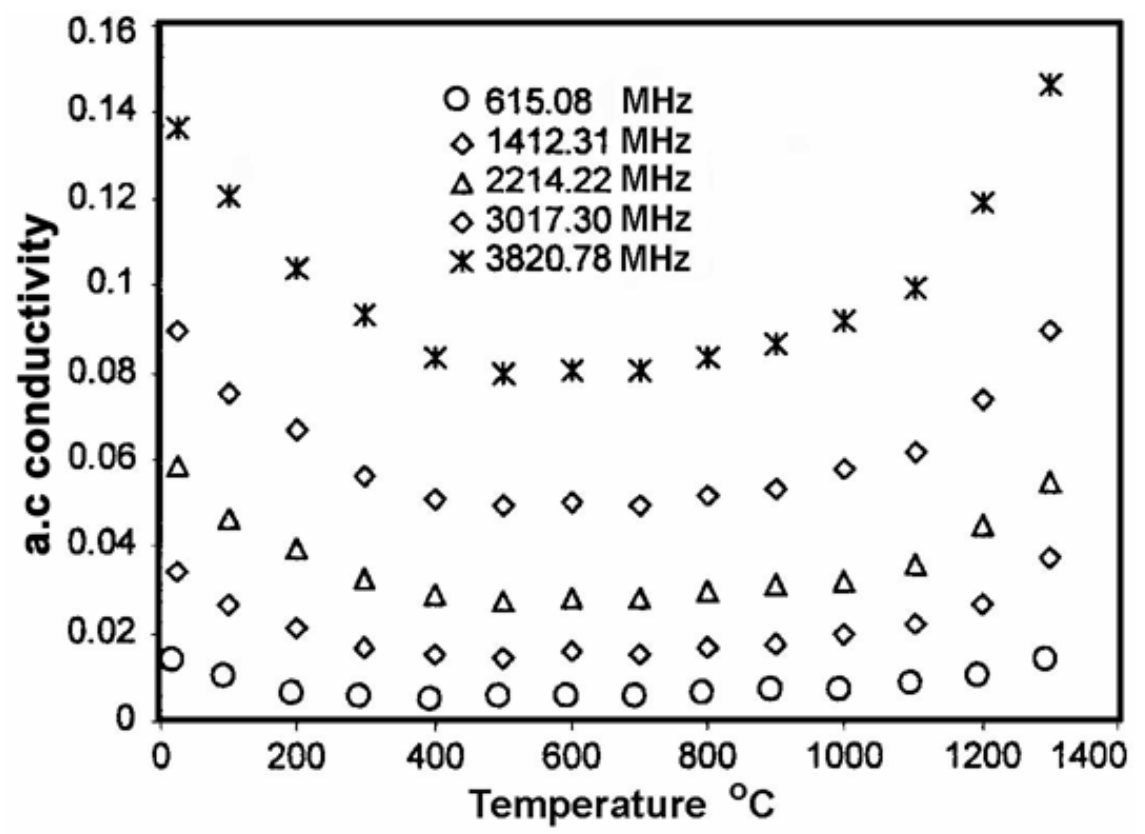

Fig. (5): Temperature dependence of a.c. Conductivity (SiC-2 mm diameter at different frequencies). 

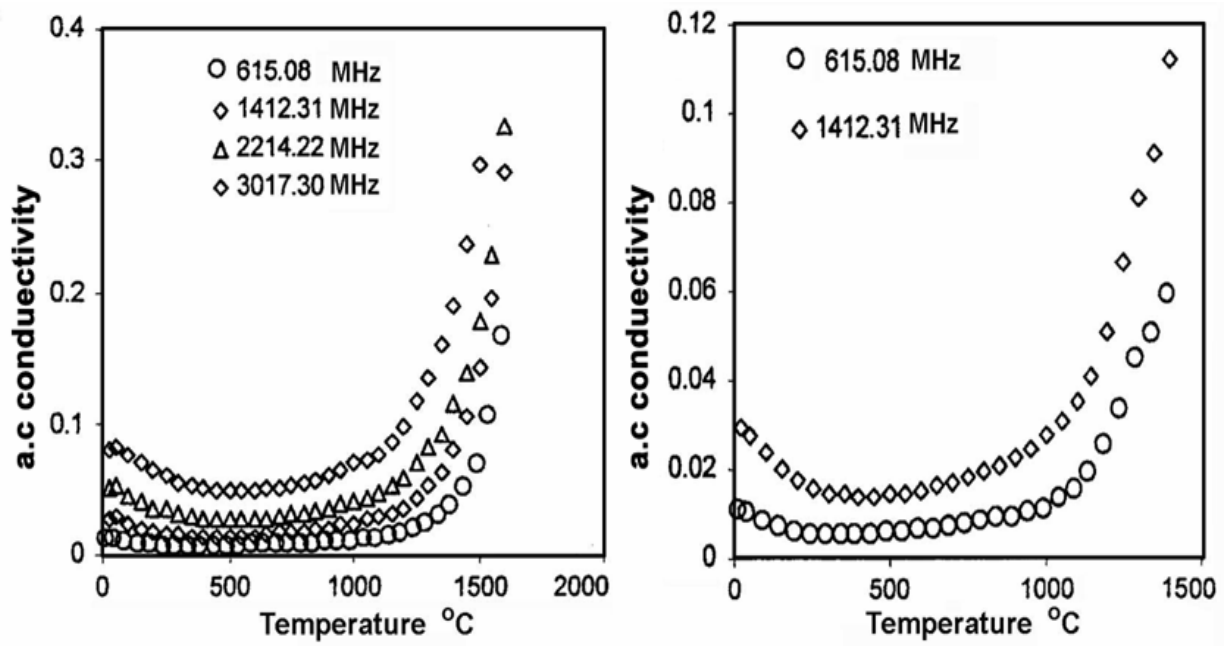

Fig. (6): Temperature dependence of a.c. Conductivity ( $\mathrm{SiC}-3 \mathrm{~mm}$ diameter at different frequencies).

Figures (5 and 6) Illustrates the temperature dependence of. $\mathrm{SiC}$ conductivity at different frequencies. It can be seen that the conductivity of $\mathrm{SiC}$ increases with increasing temperature and decreasing with the increasing frequency.

The activation energy, $U$, is the energy required for a dipole transitions between two equiprobable positions to describe the microscopic processes occurring during reorientation polarization. This concept was introduced by the modem methods [24]. The activation energy, $\mathrm{E}_{\mathrm{A}}$, can be derived by plotting the natural logarithm of the electrical conductivity, $\sigma$, versus the inverse temperature $(1 / \mathrm{T})$ and using the following equation [23]

$$
\mathrm{E}_{\mathrm{A}}=-\mathrm{k}(\mathrm{SLOPE})
$$

$\mathrm{k}$ is the Boltzman's constant and the SLOPE is the slope of $\sigma$ versus $(1 / T)$.

Only two values of the activation energy were obtained at high and low, temperature ranges by Bruce [23]. In this recent analysis, the activation energy has been obtained at each step of temperature by taking the slope of each point on Fig. 7 and 8 . The natural logarithm of the electrical conductivity, $\sigma$, versus the inverse temperature $(1 / \mathrm{T})$ for the samples of $\mathrm{SiC}$ is shown in Figs. $(7 \& 8)$. 


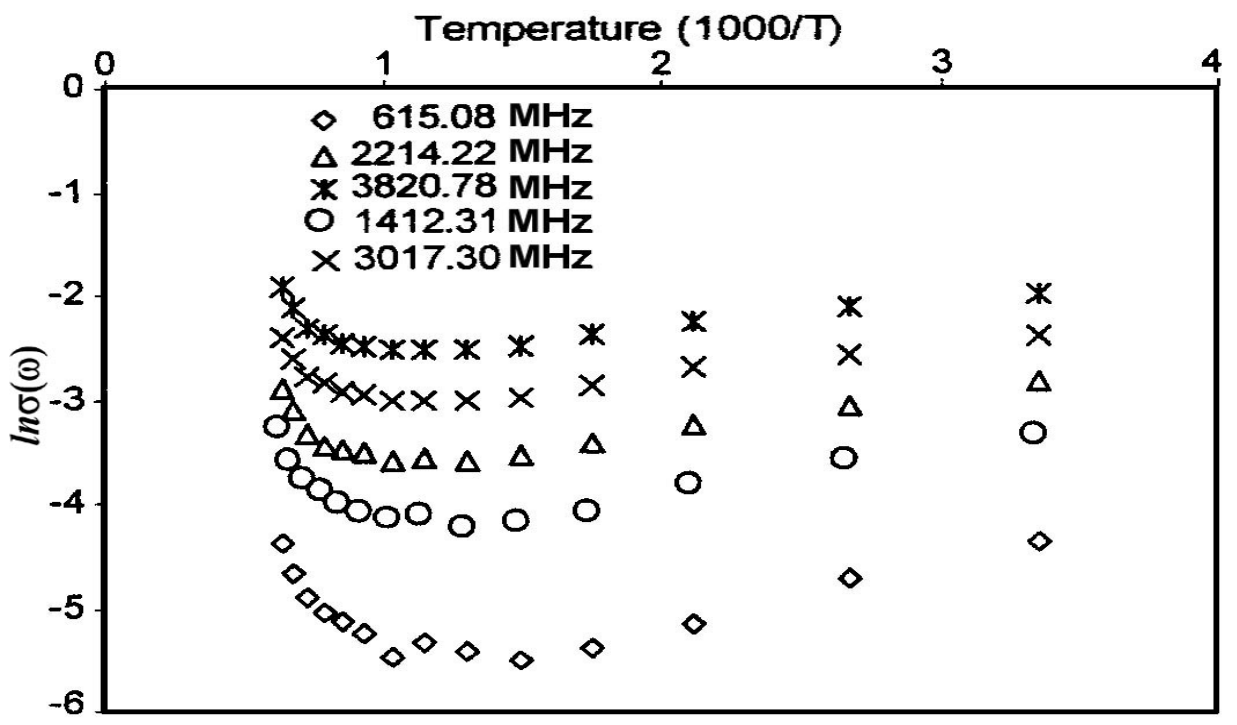

Fig. (7): Temperature dependence of $\ln \sigma(\omega)$ of $\mathrm{SiC} 2 \mathrm{~mm}$ diameter..

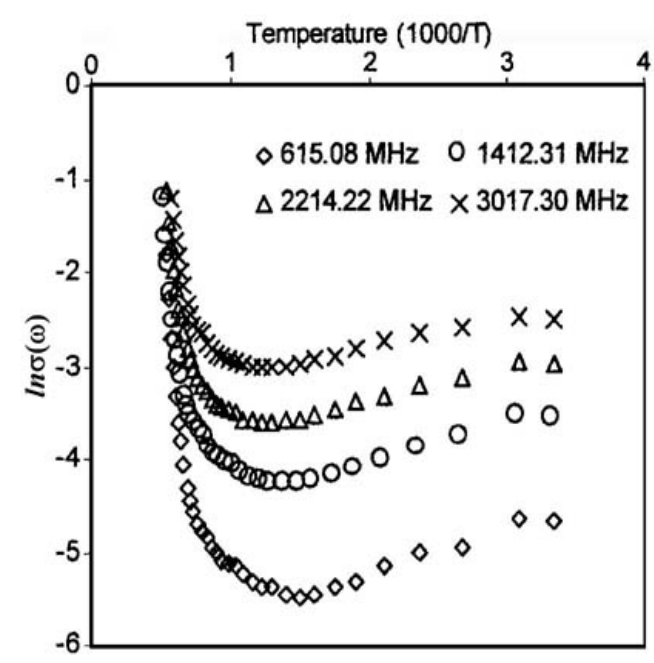

(a)

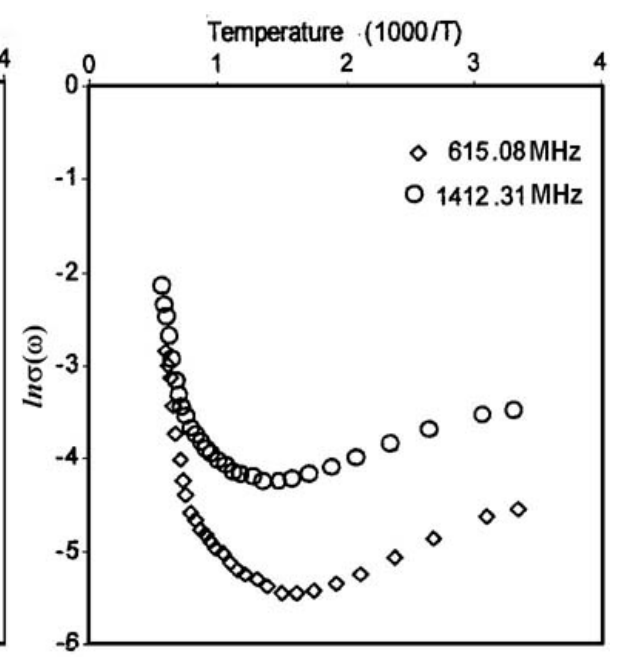

(b)

Fig. (8): Temperature dependence of $\ln \sigma(\omega)$ of $\mathrm{SiC} 3 \mathrm{~mm}$ diameter (b) $5 \mathrm{~mm}$ diameter.

It can be seen that the activation energy of the $\mathrm{SiC}$ is highly dependent on temperature specially above $500^{\circ} \mathrm{C}$. However, the frequency has no significant effect on the activations energy. Which is in consistency withe previous results [21] 


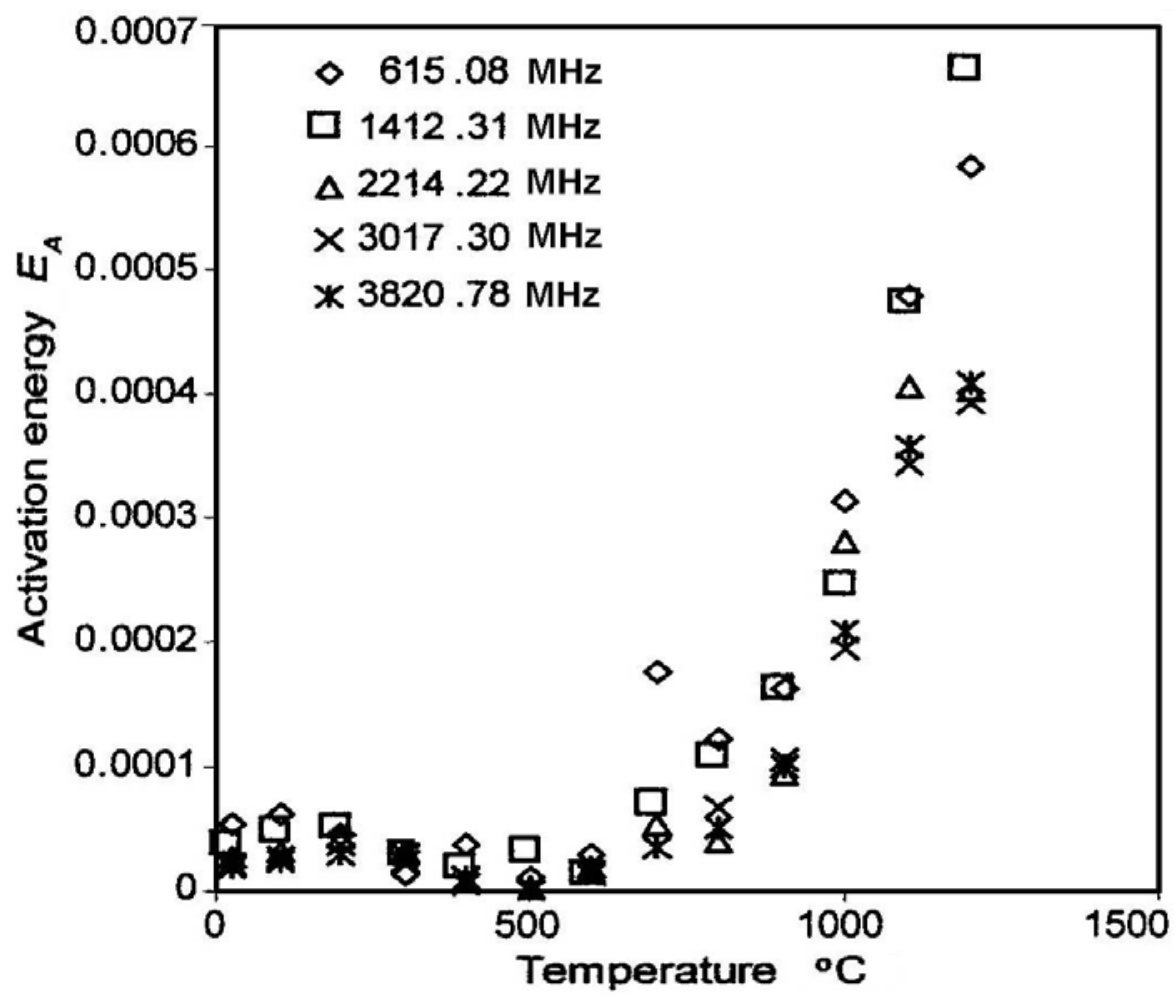

Fig. (9): Illustrates the activation energy at different temperature .

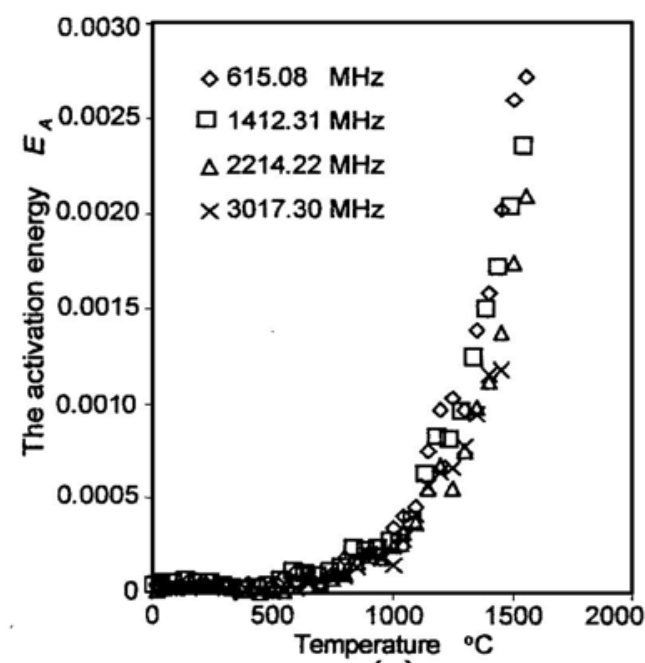

(a)

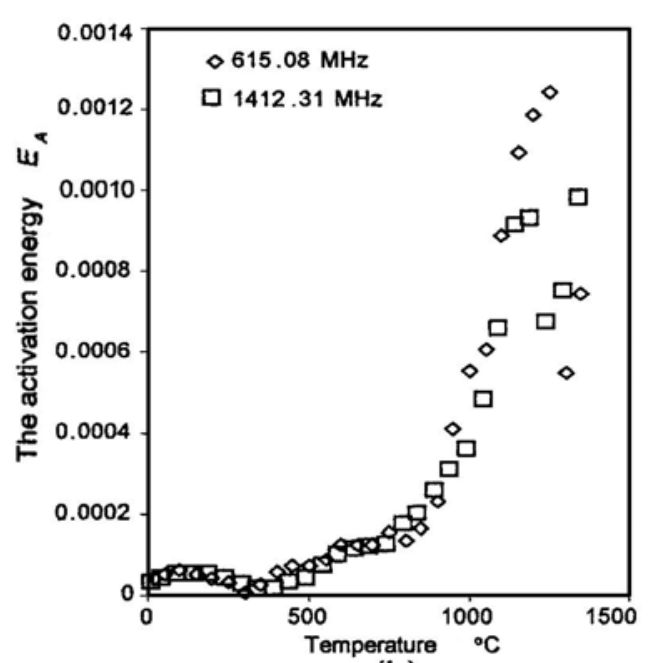

(b)

Fig. (10): The activation energy, $\mathrm{E}_{\mathrm{A}}$ of $\mathrm{SiC}$ Sample versus temperature of (a) $3 \mathrm{~mm}$ diameter (b) $5 \mathrm{~mm}$ diameter. 


\section{Conclusion:}

The experimental analyses reported herein have shown that measuring the dielectric properties of $\mathrm{SiC}$ provided a wide range of data about the microwave interactions with ceramic materials, $\mathrm{SiC}$, at high temperature in the microwave region. The complex permittivity imaginary part, $\varepsilon$ ", is the most important parameter of these measurements that it can determine a complete data of the electrical characteristics of any ceramic material. The electrical conductivity, $\sigma$, and the activation energy, $E_{A}$, were calculated using complex permittivity imaginary part, $\varepsilon^{\prime \prime}$. The changing of the complex permittivity imaginary part, $\varepsilon^{\prime \prime}$, the electrical conductivity, $\sigma$, and the activation energy, $E_{A}$, with the changing of temperature shows the thermal runaway phenomena of $\mathrm{SiC}$ presented at the same temperature degree of $1200^{\circ} \mathrm{C}$ for the above three parameters. This leads to that controlling the microwave processing of ceramics with temperature and changing both temperature and frequency will be easier with the microwave measurements of the dielectric properties of ceramic materials at high temperature.

\section{References:}

1. J.G.P. Binner, N.A. Hassine, and T.E. Cross, J. Am. Ceram. Soc. 59, 565(1995).

2. D.E. Dark, W.H. Sutton, and D.A. Lewis, J. Am. Ceram. Soc., 80, 61 (1997).

3. Ph. Boch, N. Lequeux, and P. Piluso, J. MRS. 269, 211 (1992).

4. W.H. Sutton, "Key Issues in Microwave process Technology," J. Am. Ceram. Soc., 36, 3 (1993).

5. J. Samuels, and J.R. Brandon, J. Materials Science 27, 3259 (1992).

6. R.H. Plovnick, and J.O. Kiggans, "Microwave" J. Am. Ceram. Soc., 75 (12), 3462 (1992).

7. I. Amad, R. Silberglitt, W.M. Black, H.S. Sa'adaldin, and J.D. Katz, J. MRS. 269, 271 (1992).

8. T. Takada, S.F. Wang, S. Yoshikawa, S.J. Jang and R.E. Newnham, J. Am. Ceram. Soc., 77(7), 1909 (1994).

9. B. Mikijelj, and I.E. Campisi, J. Am. Ceram. Soc, 32, 37 (1993).

10. M.E. Brito, K. Hirao, M. Toriyama, and M. Hirota, J. MRS. 430, 151 (1996).

11. C.E. Holcomhe and N.L. Dykes, J. Am. Ceram. Soc., 21, 375 (1991).

12. S.N. Kumar, A. Pant, R.R. Sood, J. Ng-Yelim, and R.T. Holt, J. Am. Ceram. Soc., 21, 395 (1991).

13. Y.L. Tian, J. Am. Ceram. Soc., 21, 283 (1991). 
14. R. M. Hutcheon, F.P. Adams and M.S. De Jong, J. Am. Ceram. Soc., 59, 215 (1995).

15. X.D. Yu, V.V. Varadan, and V.K. Varadan, J. Am. Ceram. Soc., 21, 167 (1991).

16. R.E. Newnham, S.J. Jang, M. Xu, and F. Jones, J. Am. Ceram. Soc., 21, 51 (1991).

17. S. Li, C. Akyel, R.G. Bosisio, J. IEEE, MTT-29(10), 1041 (1981).

18. B. G. Colpitts, J. IEEE, MTT-41(2), 229 (1993).

19. W. Xi, W. R. Tinga, W.A.G. Voss, and B.Q. Tian, J. IEEE, MTT-40(4), 747 (1992).

20. Z. Jian, Ch. Jiping, T. Yuling, and Q. Jinyu, J. MRS. 430, 263 (1996).

21. T. A. Baeraky, "High Temperature Measurements of The Microwave Dielectric Properties of Ceramics," Ph.D. The University of Nottingham, UK, (1999).

22. E. Nakamura and J. Furuichi, J. Phys. Soc., Japan. 15, 1955 (1960).

23. R.W. Bruce, J. Am. Ceram. Soc., 21, 107 (1991).

24. A.C. Metaxas, and R.J. Meredith, "Industrial Microwave Heating, London, Peter Peregrinus, Ltd. (1988). 